PONTIFÍCIA UNIVERSIDADE CATÓLICA DO RIO DE JANEIRO

\title{
Motivação do Consumo no Varejo de Joias \\ Percepção de Atributos das Lojas
}

\section{Bruno Chueke}

Trabalho de Conclusão de Curso

Centro de ciências socials - CCS

DePARTAMENTO dE AdMINISTRAÇÃO

Graduação em Administração de Empresas 


\section{Bruno Chueke}

\section{Motivação do Consumo no Varejo de Joias}

Percepção de Atributos das Lojas

\section{Trabalho de Conclusão de Curso}

Trabalho de Conclusão de Curso, apresentado ao programa de graduação em Administração da PUC-Rio como requisito parcial para a obtenção do titulo de graduação em Administração.

Orientador(a): Vivian Peuker

Rio de Janeiro

Novembro de 2021. 


\section{Agradecimentos}

Dedico esta conquista, em primeiro lugar, à minha família que me apoiou e me incentivou durante todo o meu percurso na faculdade para que eu chegasse até aqui. Mãe e pai, dedico a conclusão deste curso especialmente a vocês.

Ao meu irmão, por estar sempre ao meu lado, me apoiando e me compreendendo independente da situação.

Aos meus amigos, pelo suporte até aqui, pelos empurrões e conselhos, por me ouvirem e contribuírem para me manter no foco de concluir o curso.

A minha tutora Vivian pelos conselhos e acompanhamentos semanais para que eu pudesse terminar este estudo com maestria. 


\section{Resumo}

Chueke, Bruno. Motivação do Consumo no Varejo de Joias, Percepção de Atributos das Lojas. Rio de Janeiro, 2021. 30 páginas - Departamento de Administração. Pontifícia Universidade Católica do Rio de Janeiro.

Este estudo tem por objetivo avaliar o efeito da motivação hedônica e utilitária na percepção da atmosfera em uma cadeia de varejo brasileira de joias. Para fundamentar o estudo, foi realizada uma pesquisa de campo realizada com um questionário e algumas entrevistas presenciais, com a intenção de mensurar a disposição/layout da loja e 0 atendimento ao cliente, para então definir as métricas que impactam significativamente a satisfação e a intenção de recompra do cliente.

O estudo demonstra que os consumidores, em grande maioria, mostram maior satisfação em lojas que utilizam o marketing sensorial, que é uma subdivisão do marketing que tem a finalidade de trabalhar a percepção dos clientes por meio de estímulos sensoriais, ou seja, mexendo com os cinco sentidos. O comportamento dos consumidores hedônicos evidencia uma forte relação entre a disposição e as características físicas da loja e o atendimento ao cliente, e a satisfação e a intenção de recompra. Assim, é possível concluir com o presente estudo que a satisfação que o consumidor encontra na atmosfera da loja resulta na intenção de recompra.

\section{Palavras- chave}

Satisfação, Motivação Hedônica, Varejo de joias, Marketing

\section{Abstract}

Chueke, Bruno. Motivation of Consumption in Jewelry Retail, Perception of Store Attributes. Rio de Janeiro, 2021. 30 pages- Department of Administration. Pontifical Catholic University of Rio de Janeiro.

This study aims to evaluate the effect of hedonic and utilitarian motivation on the perception of the atmosphere and on the quality of care, satisfaction, experience and intention of repurchase in a Brazilian jewelry retail chain. A field 
research fulfielld with a questionnarie and some face-to-face interviews, with the intention of measuring the layout of the store and customer service, and then defining the metrics that significantly impact the customer's satisfaction and repurchase intent.

In the vast majority, utility consumers show greater satisfaction in stores that use sensory marketing, which is a subdivision of marketing that aims to work on customer perception through sensory stimuli, that is, by messing with the 5 senses. Hedonic consumers demonstrate a strong relationship between store layout and customer service, and between satisfaction and repurchase intention, which shows that the satisfaction they find in the store atmosphere and in the service itself leads to the intention of repurchase.

\section{Key-words}

Satisfaction, Hedonic Motivation, Jewelry Retail, Marketing 


\section{Sumário}

1 Introdução

1.1. Introdução ao tema e ao problema estudado 1

1.2. Objetivo do estudo $1-2$

1.3. Relevância do estudo 2-3

2 Referencial Teórico 4-9

2.1. Impacto das variáveis atmosféricas 4-6

2.2. Satisfação e motivação do consumidor $\quad$ 6-7

2.3. Comportamento do consumidor $\quad 7$

2.4. Motivações de consumo (utiliárias e hedônicas) 8

2.5. Intenção de recompra 9

2.6. Marketing sensorial no varejo 9

3 Metodologia $10-13$

3.1. Compilação dos dados 10

3.2. Formas de tratamento e análise 11

3.3. Descrição do método $12-13$

4 Análise da situação $114-20$

4.1. Pesquisa e questionário 1Erro! Indicador não definido.-17

4.1.1. Perfil dos entrevistados 1Erro! Indicador não definido.-15

4.1.2. Percepção e comportamento dos entrevistados 16-17

4.2. Análise dos resultados $17-19$

4.3. Análise do comportamento de compra $\quad 19-20$

4.4. Opiniões gerais e comparativas dos entrevistados 20-22

5 Conclusão

22-2Erro! Indicador não definido.

5.1. Resultados obtidos 23-24

5.2. Considerações finais $24-25$

6 Referências 


\section{Introdução}

De acordo com um relatório de 2019 da SBVC (Sociedade Brasileira de Varejo e Consumo), os lojistas estão transformando, progressivamente, suas lojas em ambientes mais agradáveis e estimulantes, visando um ambiente planejado para criar ou reforçar a indução do consumidor para comprar o produto. Considerando que as intenções comportamentais afetam diretamente a lucratividade da empresa (“Udo, Bagchi \& Kirs, 2010"), é extremamente importante que os varejistas se diferenciem com uma forma mais atrativa e inovadora que seus concorrentes.

\subsection{Introdução ao tema e ao problema estudado}

A ideia de que a atmosfera da loja influencia diretamente no comportamento do consumidor é pacificamente aceita na literatura de marketing "Turley \& Milliman, 2000". Esta ligação entre atmosfera e comportamento demonstra que os consumidores percebem, mesmo que de forma inconsciente, os ambientes de maneira holística e suas reações ao meio físico dependem do conjunto de efeitos ou configurações.

Entretanto, a literatura ressalta a dificuldade de mensurar aspectos intangíveis e subjetivos de um ambiente de serviço, isso porque os estilos de tomada de decisão estão se tornando cada vez mais complexos no que se refere ao processo do consumidor escolher uma loja, ficarem satisfeitos com a decisão e, possivelmente, fazer uma compra.

\subsection{Objetivo do estudo}

O objetivo deste estudo é avaliar o efeito e as peculiaridades da motivação hedônica e utilitária na percepção da atmosfera em uma cadeia de varejo brasileira de joias. O presente estudo tem o foco direcionado para o varejo, com recorte específico da avaliação pelos clientes de sua experiência no ponto de venda, com ênfase nos aspectos gerencialmente controláveis. Verificações exploratórias realizadas pela FGV-EAESP indicam que as lojas que exploram os sentidos de 
uma pessoa, os cinco sentidos humanos, garantem maior capilaridade e geram resultados superiores comparado às varejistas que não utilizam esta estratégia.

Para este estudo a rede varejista analisada será a H.Stern, uma joalheria brasileira, dedicada ao desenho e confecção de suas próprias joias. Fundada em 1945 por Hans Stern, um judeu alemão que fugia do nazismo e acabou se naturalizando brasileiro, começou com um pequeno negócio de compra e venda de pedras no Rio de Janeiro. Atualmente a empresa conta com 280 lojas espalhadas por 30 países, das quais 88 estão concentradas no Brasil, uma das marcas mais valorizadas do mundo em seu nicho, com faturamento estimado em 400 milhões de reais.

A seleção pelo grupo Stern foi devido ao parentesco do autor com um dos sócios da rede varejista, tendo assim uma maior facilidade em obter certas informações e dados, além de poder ter acesso aos consumidores mais frequentes da rede, no Rio de Janeiro.

Quando pensamos no buyer persona, ou seja, o cliente ideal de uma joalheira dessa magnitude, podemos abranger diferentes tipos de persona e faixa etárias. Em geral, a maior parcela são mulheres, com idade entre 30 e 45 anos, moradoras de bairros nobres e com uma renda mensal entre 15 e 23 mil reais. Tais números, como será melhor explorado adiante, se justificampor ser a $\mathrm{H}$. Stern uma rede varejista focada na classe alta dos países onde está sediada. Entretanto, como se verá, consultando o banco de dados da rede, é possível observar que ainda existem grupos de personas distintas que geram grande parte da receita da marca.

\subsection{Relevância do estudo}

Os fatores da experiência de compra dentro da loja física são extremamente importantes em termos práticos e acadêmicos. A percepção que os clientes têm da loja, a preferência que demonstram por alguns atributos em detrimento de outros, e a conversão dessas preferências em vendas e em retorno às lojas, são informações relevantes tanto para os gestores varejistas - pois contribuem para a administração das organizações - quanto para acadêmicos, uma vez que viabiliza aprimorar os conhecimentos sobre o varejo e sobre o comportamento do consumidor. 
Antes de mais nada, é preciso considerar se o tipo de motivação que leva o consumidor a entrar em uma loja e realizar uma compra, é hedônico ou utilitário? O consumo hedônico é o que motiva a análise de tendências, ou seja, quando o consumidor compra algo por impulso ou é motivado por suas emoções. Já a decisão de compra utilitária é motivada pela necessidade, por uma ação racional, onde os fatores de decisão são tangíveis. Tomando essa premissa como ponto de partida, Fica claro que muitos fatores no ambiente de varejo, incluindo o atendimento ao cliente, devem ser moldados de modo a auxiliar no objetivo do consumidor.

Especificamente, as motivações de compra afetam proporcionalmente o reconhecimento da necessidade do consumidor, a busca de informações e os estágios de avaliação, aquisição e pós-compra ("Puccinelli et al., 2009"). Com base nos argumentos mencionados, este estudo é relevante pois verifica como os consumidores percebem o ambiente da loja a partir da identificação do aspecto motivacional, ou seja, analisa como a atmosfera da loja afeta o atendimento ao cliente e como estes aspectos afetam a satisfação do consumidor e a intenção de recompra. Ao avaliar a atmosfera da loja, o estudo considera variáveis como limpeza, música, temperatura, iluminação, cor, disposição/layout e aroma.

Foi realizada uma pesquisa de campo, durante a pandemia, com aproximadamente 20 consumidores de joias da zona sul do Rio de Janeiro, com uma faixa etária entre 25 e 45 anos e com uma faixa de renda de $R \$ 10.000,00$ a $R \$ 25.000,00$ e foram selecionadas pessoas que já haviam adquirido algum tipo de joia.

Como dito anteriormente, esta é uma rede varejista de alto luxo, onde os produtos são direcionados estritamente para a classe A dos países onde atua. Por esta razão, para as entrevistas relizadas, e para trazer resultado mais eficaz ao estudo, limitou-se tanto a faixa etária quanto a faixa salarial, abrangendo a parcela que mais gera receita para a empresa, buscando verificar se a motivação do consumidor (hedônica ou utilitária) altera o comportamento de compra no varejo e entender melhor o papel da atmosfera da loja e do atendimento ao cliente como determinantes da satisfação e da intenção de recompra. 


\section{Referencial Teórico}

Um relatório publicado pela Adyen em 2021 demonstra que a motivação para se realizar uma compra é um influenciador importante do comportamento do consumidor, seja este hedônico ou utilitário. Assim, além de afetar a compra em si, a motivação tem um impacto direto na avaliação do cliente da atmosfera de uma loja. Seguindo neste pensamento, se os consumidores hedônicos (foco na experiência) e utilitários (foco na tarefa) se diferem nos procedimentos cognitivos que são acionados durante uma compra, os varejistas podem se utilizar desse conhecimento e combinar fatores que compõem o ambiente de vendas a fim de ativar esses procedimentos cognitivos.

O referencial teórico deste estudo discute os motivadores intangíveis e subjetivos no ambiente da loja de joias.

\subsection{Impacto das variáveis atmosféricas}

“Bitner (1992)" estudou a integração dos estudos empíricos e teorias sobre o ambiente da loja, criando um modelo conhecido como servicescape. Esse modelo designa estímulos holisticamente percebidos e utilizados na criação do ambiente físico onde ocorre o serviço. Em locais específicos, como joalherias, o cenário assume um importante papel, pois influencia diretamente na percepção de qualidade do serviço. Esse ambiente integrado, é moderado pelas reações de consumidores e colaboradores que criam respostas internas que são afetadas por fatores cognitivos, emocionais e psicológicos, ou seja, essas respostas direcionam os consumidores na aproximação ou rejeição de uma loja.

Os consumidores percebem a atmosfera de uma loja de forma holística e a sua resposta ao ambiente físico depende de um conjunto de efeitos, os quais são bem difíceis de prever. De acordo com "Singh et al. (2014)" os atributos da atmosfera de uma loja e da imagem dos colaboradores, tais como música, temperatura ambiente, layout, vestimenta, aroma e atitude dos atendentes, são 
considerados pelos consumidores como fatores críticos. "Bitner (1992)" desenvolveu um modelo ambiental tridimensional composto por:

a) Condições Ambientais: temperatura, iluminação, música, aroma, fatores que atacam os sentidos do ser humano;

b) Espaço / Função: ambientes de serviço existentes para atender especificamente as necessidades do consumidor;

c) Sinais, Símbolos e Design: artefatos dispostos interna e externamente que definem a identidade da loja.

Inspirado na obra de Bitner, este estudo utiliza a classificação de atributos de loja em três dimensões, ou seja, atributos relacionados a produtos, atributos relacionados à qualidade do serviço e atributos relacionados à loja. Essa classificação é a mais aceita e eficiente de acordo com a literatura sobre o tema e considerando a opinião de especialistas como gerentes de joalherias de alto nível.

A atmosfera da loja, portanto, é um elemento estratégico que deve ser moldado de acordo com o que o consumidor valoriza em um ambiente específico, de maneira holística e integrada, para assim obter uma vantagem competitiva no mercado. Para o trio "Sheth, Mittal e Newman (2001)", a atmosfera da loja pode influenciar o consumidor a permanecer nela ou sentir vontade de sair dali imediatamente. Isso nos mostra que a atmosfera tem a capacidade de afetar os clientes não apenas cognitivamente, mas emocionalmente também.Como os consumidores percebem o ambiente ao seu redor com seus sentidos é um aspecto crucial no processo de compras e das respostas comportamentais.

A música de fundo, por exemplo, aumenta a excitação do consumidor e por consequência resulta em melhores resultados de vendas, melhora as atitudes em relação à loja ("Chebat J., Chebat \& Vaillant, 2001"), afeta o tempo de permanência na loja e a compra do cliente. Da mesma forma, a limpeza, o cheiro, a iluminação e o layout da loja têm um papel priomordial na intenção de compra dos consumidores, e até mesmo os produtos expostos à venda devem ser exibidos de forma a atrair consumidores, impactando fortemente a intenção de compra e a percepção sobre o produto ("Ballantine et al. 2010"). 
"Sherry e McGrath (1989)" descobriram que o ambiente da loja, desde o design estrutural e decoração até a arrumação dos decorativos e estratégias de rearranjo, carregam uma mensagem poderosa a todos os clientes que entram na loja, sendo a experiência um presente que cria um ambiente persuasivo. Por isso, este estudo foi desenvolvido com a intenção de investigar o impacto coletivo de todas as principais variáveis atmosféricasdado que os objetivos do consumidor desempenham um papel importante na determinação de como os estes percebem o ambiente de varejo e os diversos elementos do mix de marketing.

\subsection{Satisfação e motivação do consumidor}

A satisfação do cliente pode ser definida como o sentimento ou efeito positivo, que se baseia na comparação entre o nível percebido de oferta ou resultados dos clientes e o nível esperado de ofertas ou resultados. "Nair (2018)" explorou a relação entre as intenções de patrocínio e os atributos da loja, ao mesmo tempo em que considerou a satisfação do cliente como mediador. O estudo concluiu que o estilo de vida não se qualifica como moderador para essas relações.

Da mesma forma, "Yie La (2004)" realizaram um estudo para diferenciar entre clientes de baixa lealdade e alta lealdade, referindo-se ao efeito da satisfação do cliente na intenção de recompra, e a qualidade do serviço foi encontrada como um fator importante que influencia a satisfação do consumidor. No entanto, nenhuma evidência sobre a lealdade do consumidor foi estabelecida em seu estudo, e ficou claro que a qualidade do serviço, para este tipo de pesquisa, deve ser vista sob a perspectiva dos clientes.

A ideia de satisfação do cliente pode ser definida como um julgamento ao qual se submete um produto ou serviço. É a sensação que o consumo oferece ao cliente, além de ser um resultado de um padrão de prazer versus desprazer (“Oliver, 1999"). Satisfazer um cliente é um preditor muito importante quando pensamos no comportamento futuro do mesmo, isso porque um cliente satisfeito tende a comprar na mesma loja novamente, assim como também, são menos suscetíveis às ofertas dos concorrentes e mais propensos a fazer comentários positivos a outras pessoas sobre a marca que gostaram. 
Da mesma maneira, um cliente insatisfeito pode influenciar 0 comportamento de outras pessoas e prejudicar a reputação de umamarca. Basicamente, a satisfação do consumidor normalmente está associada:

- Ao aumento da lealdade do consumidor;

- Uma redução na elasticidade do preço;

- Uma redução nos custos de captação de novos clientes

- Aumento da reputação da empresa;

Em resumo, pode-se afirmar que, como consumidores satisfeitos têm maior probabilidade de permanecerem leiais a marca, as intenções comportamentais influenciam diretamente na lucratividade da empresa (“Udo et al. 2010").

Usando o estudo de "Overby e Lee (2006)" como exemplo, constatou-se que os consumidores estão cada vez mais considerando o valor utilitário e hedônico como fatores importantes para decidir entre lojas. $O$ estudo avaliou também que o valor utilitário motivacional é um fator mais forte comparado ao valor hedônico. Essa descoberta foi muito valiosa, uma vez que estes valores são parâmetros relevantes para a previsão dos resultados das intenções.

\subsection{Comportamento do consumidor}

Sobre o comportamento do consumidor, é importante iniciar mencionando um aspecto importante. O ato de um cliente falar positivamente sobre os produtos e serviços de uma empresa e recomenda-los a outras pessoas é conhecido como "boca a boca". Geralmente, este comentário positivo leva à geração dos promotores da marca ou empresa, o que influencia outras pessoas a comprar da mesma empresa, marca ou loja. Espera-se que os clientes que estão altamente satisfeitos com os produtos e serviços expressem esse comportamento de satisfação via repercussão. Os dois componentes do compromisso, ou seja, compromisso afetivo e compromisso contínuo, mediam totalmente a relação entre satisfação da marca e ambas as intenções de recompra e intenções de defesa (“Fullerton, 2005”).

\subsection{Motivações de Consumo (Utilitárias \& Hedônicas)}


Um cliente consome um produto por diferentes razões. Às vezes, fazer compras é uma atividade direcionada com um objetivo fixo, por exemplo: comprar um produto $X$ porque precisa dele por questão de necessidade/utilidade., Outras vezes, é uma atividade recreativa onde a experiência e diversão são a própria atividade de fazer compras. Por isso é de suma importância compreender as motivações utilitárias e hedônicas, pois elas são, como pretende-se demonstrar aqui, influenciadores importantes no comportamento de consumo.

Por um lado, analisa-se que as motivações utilitárias refletem objetivos de compra racionais, focados na funcionalidade ou no cumprimento de uma tarefa específica, enquanto as motivações hedônicas se remetem às emoções e a experiência do consumidor ("Babin, Darden \& Griffin, 1994; Büttner et al., 2013"). Em resumo, os ditos utilitários apreciam quando um produto pode ser comprado de maneira deliberada e eficiente, já os hedônicos, apreciam a experiência por trás da compra.

As compras utilitárias são um meio para atingir o fim, esse tipo de compra busca eficiência, assim, aspectos como limpeza, área de vendas, exposição dos produtos, iluminação e cor estão relacionados à variedade de produtos e à praticidade de achá-los. O consumidor utilitário é motivado por qualidades como, segurança, qualidade do produto, função e valor em dinheiro, neste cenário a elasticidade é muito alta, ou seja, os consumidores utilitários são muito sensíveis a variações no custo e no valor percebido, e prestam menos atenção a fatores emocionais e sociais ("Barbopoulos \& Johansson, 2017").

Na compra hedônica, os consumidores possuem uma orientação experiencial e buscam explorar diferentes tipos de estímulos durante o processo de compra, isso porque este tipo de comprador enxerga o processo como uma tarefa agradável. A motivação hedônica foca em objetivos secundários como prazer, conforto e estímulo, e deixa a utilidade e as normas racionais para um segundo plano, podendo resultar em reduçãoda eficácia de muitas estratégias utilizadas de mudança de preço, de comportamento, campanhas de informação e incentivos.

\subsection{Intenção de recompra}

A intenção de recompra pode ser definida como a chance de os clientes revisitarem e fazerem compras repetidas ou semelhantes da mesma loja no futuro. 
Clientes satisfeitos são mais propensos a revisitar, recomendar e recomprar as ofertas da mesma loja, "Chang et al. (2015)" tentou investigar essas questões e descobriu que os funcionários de vendas e os atributos da atmosfera da loja afetam positivamente a satisfação do consumidor.

A intenção de recompra possui uma grande importância no contexto acadêmico e empresarial e, por este motivo, diversos pesquisadores salientam que ainda existem lacunas para aprofundar o conhecimento. Compreender 0 fenômeno que leva o consumidor a ter a intenção de recompra de certo produto e/ou serviço de uma marca é um aspecto chave para o sucesso das empresas. Diante disso, o presente estudo analisa a influência do valor percebido, do comprometimento afetivo, do comprometimento normativo e da propaganda boca a boca positiva sobre a intenção de recompra de joias.

\subsection{Marketing sensorial no varejo}

Explorar os cinco sentidos humanos no ponto de venda está alinhado ao objetivo de valorizar os pequenos momentos pelos quais as pessoas passam. Afinal o comportamento do consumidor está cada vez mais atrelado às intenções momentâneas e à sua proximidade e identificação com as marcas.

Todo processo de decisão de compra está intimamente ligado aos estímulos instantâneos, logo, é essencial criar métodos criativos que possam prender a atenção dos clientes e proporcionar situações agradáveis e fortes o suficiente para serem capazes de fidelizá-los. Pensar em detalhes para proporcionar uma experiência agradável e única ao cliente é sinônimo de estabelecer vínculos cada vez mais diretos e personalizados. São estes detalhes na experiência que fortalecem a relação entre o consumidor e a marca, consequentemente aumentando as vendas, pois, como se viu, uma boa experiência sensorial também contribui para que a pessoa queira repetir a experiência. 


\section{Metodologia}

Este estudo mescla pesquisas quantitativas e qualitativas. Especificamente, foi utilizada uma pesquisa de campo em bairros nobres da zona sul da cidade do Rio de Janeiro, para coletar dados com consumidores da cadeia de varejo de joias. Foi realizado um questionário com 18 perguntas na forma de múltipla escolha, às quais foram compiladas e analisadas através do Google Analytics para podermos discernir a influência que cada variável atmosférica exerce sobre os consumidores, além do comportamento dos mesmos sobre a influência destas variáveis atmosféricas.

\subsection{Compilação dos dados}

Dentro do segmento de joias, para esta coletânea de dados, foi escolhida uma das maiores varejistas de joias brasileira. A amostra escolhida para este estudo abrange consumidores entre 25 e45 anos que costumam comprar na joalheira. $A$ coleta foi realizada em diferentes horários do dia e em diferentes dias da semana, o período da coleta foi entre setembro e outubro de 2021.

O questionário foi montado com dois filtros de pesquisa: interpretação da loja e se já haviam comprado na mesma, e, se ambos fossem positivos, a pesquisa seguia, caso contrário, encerraria a pesquisa nesse ponto. A partir deste panorama, os itens foram compilados e as variáveis mensuradas conforme o valor motivacional utilitário ou hedônico do consumidor, avaliação do grau de intensidade dos componentes da atmosfera da loja e frequência na rede varejista, além das variáveis de satisfação e intenção de recompra ("Teixeira \& Hernandez, 2012"). No total, 78 indivíduos responderam ao questionário, dos quais apenas 67 (70\%) eram válidos, excluímos aqueles casos em que os participantes não tinham conhecimento da loja ou não haviam comprado nela, resultando em uma amostra composta majoritariamente por mulheres, com idade média de 32 anos. 


\subsection{Formas de tratamento e análise}

As joias estão incorporadas na cultura humana há muito tempo como um símbolo de prosperidade, riqueza e fortuna. São utilizadas diariamente para a reforçar a autoestima dos consumidores, e são úteis para classificar o status social de um usuário. Como resultado, as joias se tornaram uma parte importante do dia a dia das pessoas "(Sanguanpiyapan \& Jasper, 2010)".

Os consumidores em geral escolhem comprar em um ponto de venda específico pois este oferece cinco características fundamentais: boa seleção de mercadorias, variedade de faixas de preço, produtos que atendem às necessidades do cliente, horário e local convenientes "(Sanguanpiyapan \& Jasper, 2010)". Além disso, os consumidores tendem a corresponder suas motivações de compra funcionais e não funcionais aos atributos do varejo ao estabelecer suas preferências de compra de joias nos pontos de venda.

Os consumidores de joias são caracterizados e segmentados por necessidades específicas completamente distintas. Existem, por exemplo, compradores do sexo masculino e compradores do sexo feminino, compradores de joias finas e compradores de bijuterias, compradores de itens para presente e itens para si próprio. Esses segmentos se sobrepõem e se cruzam, exigindo que os varejistas se concentrem em segmentos específicos e não no mercado total em resposta ao tipo de consumidor.

O sucesso do varejista está atrelado ao seu entendimento das diferentes personalidades que compõem o mercado e então da sua capacidade de apresentar os tipos de produtos, preços e experiências de compra que esse comprador em particular busca. Por outro lado, é bem provável que a distribuição das regras de escolha usadas pelos consumidores para a compra de joias forneça perspectivas táticas ou operacionais em relação à concorrência no varejo.

\subsection{Descrição do método}

Após a exclusão dos indivíduos inválidos para a pesquisa, resultou-se em uma amostra composta por 67 pessoas, sendo $75 \%$ do gênero feminino e $25 \%$ do gênero masculino. A idade média da amostra foi de 22,1 com um desvio padrão 
de $3,51(\mathrm{DP}=3,51)$, onde $70 \%$ da amostra tinha entre $25-25$ anos e os $30 \%$ restantes entre $36-45$.

Para as análises quantitativas, foi utilizado um teste de hipótese conhecido como "t student", o qual é utilizado para comparar os dois sexos em uma distribuição normal, com isso conseguimos avaliar se existe ou não uma diferença significativa entre as médias do sexo masculino e feminino para cada variável atmosférica.

As informações obtidas foram cruzadas e analisadas de forma comparativa, obtendo assim informações valiosas sobre os gatilhos motivacionais femininos e masculinos. Os participantes femininos mostraram uma tendência de compra hedônica mais alarmante em comparação aos entrevistados masculinos, estes últimos apontam para um perfil de compra mais eficiente e ágil, ou seja, um perfil com tendência utilitária.

Por outro lado, enquanto o questionário foi utilizado para análises numéricas e estatísticas, foram realizadas, paralelamente, entrevistas para análises qualitativas do caso em questão. Nesta etapa exploratória, foram realizadas 20 entrevistas pessoais realizadas durante 1 semana por "Zoom" com consumidores da marca, com a intenção de identificar padrões de comportamento e algumas reações dos entrevistados. Foram realizadas entrevistas individuais, com um roteiro de perguntas aberto para que não enviesasse os entrevistados. As perguntas foram sobre sobre o comportamento de compra, com a intenção de compreender quais os gatilhos que interferem na relação da marca com os entrevistados.

As entrevistas foram divididas em três partes, a primeira sobre as motivações de compra, utilizando a teoria de necessidade de Maslow como base, que é uma teoria da Psicologia proposta por Abraham Maslow em artigo conhecido como "A teoria da Motivação Humana". Maslow se baseia na ideia de que cada ser humano se esforça para satisfazer suas necessidades, sejam elas profissionais ou pessoais. A teoria é dividida em cinco categorias de necessidades humanas: fisiológicas, segurança, afeto, estima e as de auto realização. Este esquema proposto por Maslow, apresenta uma divisão hierárquica em que as necessidades consideradas de nível mais baixo devem ser satisfeitas antes das necessidades de nível mais alto. 
A segunda parte teve a intenção de compreender os principais fatores motivacionais que os entrevistados levam em consideração na hora de escolher aonde comprar o que desejam. Conhecendo o comportamento dos clientes e os fatores que impulsionam sua decisão de compra, uma empresa poderá antecipar as principais tendências, atrair e reter mais consumidores, elaborar melhores as estratégias publicitárias e agir com mais fundamento para gerenciar as suas ações e tomar decisões mais embasadas.

Para entender melhor sobre o comportamento do consumidor, é essencial pensar em sua jornada, em primeiro lugar. Em seguida, é muito importante dar enfoque sobre os elementos que o influenciam, por isso nesta segunda etapa, as repostas foram classificadas em quatro categorias: preço, indicação, qualidade e fama, assim conseguimos discernir a influência que cada categoria possui sob os compradores.

$\mathrm{Na}$ terceira e última parte da entrevista, as perguntas foram direcionadas na intenção de entender especificamente a influência que os valores emocionais dos participantes tinham sobre sua escolha por um produto ou marca.

Estamos vivendo em uma era experimental, onde a relação do consumidor com a marca é tão importante quanto a qualidade e o preço do produto, ou seja, o vínculo emocional de uma marca com o consumidor interfere diretamente no processo de decisão de compra. Por isso, saber como a marca faz os consumidores se sentirem é fundamental para entender a experiência do cliente. 


\section{Análise da situação}

Com o intuito de analisar a satisfação do cliente, foi elaborado um questionário, fundamentado em conceitos que visam identificar a percepção dos clientes com relação às variáveis atmosféricas dos pontos de venda.

\subsection{Pesquisa e questionário}

O questionário foi a ferramenta escolhida para a pesquisa e obtenção dos dados necessários para a análise do nível de satisfação dos clientes da empresa H. Stern.

De acordo com "Amaro et. al (2005)", um questionário é uma ferramenta de investigação que visa recolher informações baseando-se, normalmente, na inquisição de grupos representativos da população em estudo. A pesquisa quantitativa faz o uso de questionários como um de seus instrumentos de pesquisa. Segundo "Manzato e Santos (2008)", a pesquisa quantitativa, de modo geral, é usada quando se quer medir opiniões, reações, sensações, hábitos e atitudes de um público-alvo específico, através de uma amostra que represente este público de forma estatisticamente comprovada.

De acordo com o objetivo geral, a pesquisa realizada neste estudo apresenta caráter exploratório e descritivo. A pesquisa descritiva tem como objetivo a descrição das características de uma população, fenômeno ou experiência, onde ao final, têm-se relacionado e analisado muitas informações sobre o assunto em questão.

\subsubsection{Perfil dos entrevistados}

Como estamos analisando os consumidores de uma rede varejista de alto luxo, onde os produtos são direcionados para a alta classe dos países onde atua, 
limitamos tanto a faixa etária quanto a faixa salarial, abrangendo a população que mais gera receita para a empresa.

Foi realizado paralelamente uma pesquisa via questionário, a qual 71 pessoas responderam, porém só foram validos 67 perfis, bem como entrevistas individuais com um grupo que abrange um total de 20 pessoas, sendo 6 do sexo masculino e 14 do sexo feminino, de 25 a 45 anos, de classes A e B. Na pesquisa foram identificadas 10 pessoas de classe $A$, seis de classe $B 1$ e quatro de classe B2 de acordo com o Critério Brasil 2015 (ABEP) que realiza a segmentação econômica através do levantamento de características domiciliares. O perfil dos entrevistados, assim como suas respectivas características, pode ser observado na tabela abaixo, na qual os nomes foram ocultados para manter a privacidade dos participantes.

Tabela 1 - Perfil dos participantes das entrevistas pessoais

\begin{tabular}{|l|c|c|c|}
\hline & IDADE & SEXo & CLASSE \\
\hline ENTREVISTADO 1 & 25 & Masculino & A \\
\hline ENTREVISTADO 2 & 29 & Feminino & A \\
\hline ENTREVISTADO 3 & 33 & Feminino & B1 \\
\hline ENTREVISTADO 4 & 41 & Masculino & B1 \\
\hline ENTREVISTADO 5 & 45 & Feminino & A \\
\hline ENTREVISTADO 6 & 27 & Masculino & A \\
\hline ENTREVISTADO 7 & 26 & Feminino & A \\
\hline ENTREVISTADO 8 & 30 & Feminino & B2 \\
\hline ENTREVISTADO 9 & 37 & Feminino & B2 \\
\hline ENTREVISTADO 10 & 25 & Feminino & B1 \\
\hline ENTREVISTADO 11 & 28 & Feminino & A \\
\hline ENTREVISTADO 12 & 31 & Feminino & B1 \\
\hline ENTREVISTADO 13 & 34 & Masculino & B2 \\
\hline ENTREVISTADO 14 & 41 & Feminino & A \\
\hline ENTREVISTADO 15 & 43 & Masculino & B1 \\
\hline ENTREVISTADO 16 & 44 & Feminino & A \\
\hline ENTREVISTADO 17 & 37 & Feminino & B2 \\
\hline ENTREVISTADO 18 & 36 & Feminino & A \\
\hline ENTREVISTADO 19 & 26 & Masculino & A \\
\hline ENTREVISTADO 20 & 33 & Feminino & B1 \\
\hline FOn: do auto & & \multicolumn{3}{|l}{}
\end{tabular}

Fonte: do autor 


\subsubsection{Percepção e comportamento dos entrevistados}

Esta coletânea de perguntas buscou compreender o comportamento de compra e como os entrevistados se relacionam com a marca. Na primeira parte do questionário, os participantes foram convidados a responder sobre quais seriam suas motivações de compra, para podermos classificar os participantes como hedônicos ou utilitários.

As respostas foram compiladas e agrupadas em cinco categorias base: preço, qualidade dos produtos, indicação de colegas, fama da marca e aprendizado. As respostas dos entrevistados foram bem divididas, mas foi possível observar uma forte tendência de pessoas optando por empresas que se identificam ou que possuam um branding chamativo. Veja-se, nesse sentido, um exemplo de um trecho extraído das respostas de um dos questionários: "Quando estou em dúvida entre uma marca ou outra, sempre escolho a que tem o melhor branding, odeio quando a marca que estou acostumada a comprar não tem o que eu quero, dai eu busco por marcas semelhantes que pareçam legais e bonitas.".

Através das respostas foi possível observar a tendência das pessoas de se importarem com a imagem e fama que a empresa transmite, mostrando um grande engajamento socioambiental e de identificação de valores. Nesta categoria, os entrevistados, em maioria, priorizaram marcas que transmitem uma causa que valorizam, deixando de consumir de marcas que vão contra os seus valores. Para materializar essa conclusão, observe-se mais um trecho retirado do questionário: "[...] me sinto muito influenciada pelas causas sociais, me recuso a comprar de marcas que fazem testes em animais ou têm atitudes racistas, dou preferencia para as marcas que fazem referência a preceitos que eu concorde.".

Dentre as diferentes lógicas de tipificação do comportamento do consumidor podemos perceber uma tendência de acirramento da dicotomia entre o consumo hedônico e a decisão utilitária, que está sendo motivada, em grande parte, pela diminuição do poder de compra dos brasileiros, o que acaba estimulando novas práticas de decisão de compra.

É nítida a percepção, pelas respostas das entrevistas, que mesmo um comprador com perfil hedônico, pode priorizar o consumo utilitário de vez em quando, pois mesmo que este consumidor goste do programa de ir as compras e 
valorize a experiência por trás, tem momentos onde a urgência fala mais alto e o consumidor busca por marcas eficientes, rápidas e baratas, como é o caso do entrevistado 1. Veja-se a resposta: "Cara, eu gosto muito de marcas que trazem uma experiência maneira na hora da compra, mas tem vezes que eu preciso de alguma coisa urgente, nesse caso eu vou atrás de marcas que sejam mais em conta e que tenha um processo rápido de compra".

Os consumidores adentram no cenário de recessão revendo suas práticas cotidianas de consumo. Em momentos de crise, os compradores que tendem a praticar o consumo hedônico com maior facilidade, são aqueles que possuem maior percentual de endividamento, e é justamente esta relação natural que diminui a capacidade de compra do consumidor hedônico e por consequência afeta as vendas de produtos mais supérfluos, fomentando cada vez mais uma tendência pró decisão de compra utilitária, onde o preço baixo e a possibilidade denegociação se tornam cada vez mais atraentes e corriqueiros.

"Valorizo muito as marcas em que já comprei e fui bem atendido ou marcas onde o layout é diferente, quando faço uma boa compra, sempre indico para os meus amigos e provavelmente voltarei a comprar na mesma loja no futuro". Em mais esse trecho dos formulários da pesquisa, percebe-se que um cliente com uma percepção positiva da marca também tem uma maior disposição de comprar de forma recorrente, logo além do varejista reduzir esforços e gastos com novas abordagens de venda, a marca potencializa seus resultados dessa outra forma e ainda assim aumenta a eficácia do marketing.

Todavia, quando um cliente tem uma experiência negativa, comprando um produto quebrado, não sendo atendido adequadamente, quando são ignorados ao solicitarem devoluções ou quando não fazem parte de uma estratégia de pósvenda, por exemplo, é construída uma percepção negativa que gera um descontentamento progressivo com a marca.

A percepção do cliente é extremamente importante para determinar o tipo de imagem que uma marca almeja construir. É mais fácil e menos oneroso criar um ambiente favorável para que a percepção do cliente seja positiva desde o seu primeiro contato com a marca, do que corrigir uma percepção negativa que o cliente já teve. 
Qualquer negócio depende de percepções positivas, tanto para fazer com que o cliente avance no funil de vendas quanto para desenvolver abordagens mais eficientes em outros momentos. Entretanto, os clientes não devem apenas se sentir bem comprando de tal marca, é preciso prover experiências cada vez mais sofisticadas e qualificadas, para que eles percebam o valor agregado contido nos produtos e serviços que estão consumindo.

Algo que chamou bastante atenção no decorrer do estudo foi a grande quantidade de entrevistados afirmando se sentirem afetados ou atraídos por lojas que utilizam o marketing sensorial, seja com uma música de fundo, um aroma agradável ou uma simples disposição de loja que chame a atenção. "[...] admiro muito as lojas que têm o seu próprio cheiro, aquele que te faz lembrar dela só de sentir, até mesmo as joalherias que colocam uma música suave e tranquila me fazem sentir mais à vontade e confortável comprando ali."

\subsection{Análise dos resultados}

A amostra do estudo era composta por $75 \%$ dos indivíduos de gênero feminino e $25 \%$ do gênero masculino, em relação a idade dos entrevistados, o valor médio é de 22,1 ( $D P=3,51$ ), tendo $70 \%$ entre 25 e 35 e os restantes $30 \%$ entre 36 e 45 .

Foram cruzados os valores médios obtidos nas diferentes dimensões e verificamos diferenças significativas entre participantes masculinos e femininos (Tabela 2 abaixo). Os entrevistados do sexo feminino apresentam médias maiores em quatro das dimensões hedônicas apresentadas: "Aventura na compra", "Gratificação na compra", "Compra para terceiros" e "Procurar novidades".

Estes valores são compatíveis com os resultados obtidos por "(Bellenger e Korgaonkar, 1980)" que apontam para um perfil de comprador hedónico (comprador recreativo) com uma porcentagem de consumidores femininos superior ao comprador utilitário (compra por conveniência).

Confirmando também as investigações feitas por "(Haanpää, 2005; Kim, 2006)" às quais apontam para grupos de compradores hedônicos com maior porcentagem de indivíduos femininos. Podemos observar abaixo a tabela com as 
médias para cada seção da pesquisa, a qual foi essencial para as análises comparativas entre as médias amostrais.

\begin{tabular}{|c|c|c|c|c|}
\hline \multirow[b]{2}{*}{ Dimensões } & \multirow[b]{2}{*}{ Itens da escala } & \multirow[b]{2}{*}{$\begin{array}{c}\text { M } \\
(D P)\end{array}$} & \multicolumn{2}{|c|}{ Teste T-Student } \\
\hline & & & Sexo & $\begin{array}{l}M \\
(\mathrm{DP})\end{array}$ \\
\hline \multirow{3}{*}{ Aventura na compra } & Para mim ir às compras é uma aventura. & \multirow{3}{*}{2,99} & & \\
\hline & Para mim ir às compras é estimulante. & & & \\
\hline & Ir às compras faz-me sentir no meu próprio universo. & & Ms & 2,69 \\
\hline \multirow{3}{*}{ Gratificação na compra } & $\begin{array}{l}\text { Quando me sinto pra baixo, vou às compras para } \\
\text { me sentir melhor. }\end{array}$ & \multirow{3}{*}{2,82} & \multirow{2}{*}{ Fem } & \multirow{2}{*}{3,16} \\
\hline & $\begin{array}{c}\text { Vou às compras quero oferecer a mim } \\
\text { algo especial. }\end{array}$ & & & \\
\hline & $\begin{array}{c}\text { Para mim ir às compras é uma forma de aliviar } \\
\text { o estresse }\end{array}$ & & Ms & 2,40 \\
\hline \multirow{3}{*}{ Compra para os outros } & $\begin{array}{l}\text { Gosto de comprar para os outros pois quando eles } \\
\text { se sentem bem, eu sinto-me bem. }\end{array}$ & \multirow{3}{*}{3,68} & Fem & 3,90 \\
\hline & Gosto de comprar para os amigos e família. & & & \\
\hline & $\begin{array}{c}\text { Gosto de ir às compras buscar o presente } \\
\text { perfeito para alguém. }\end{array}$ & & Ms & 3,41 \\
\hline \multirow{3}{*}{ Compra pelo valor ideal } & $\begin{array}{c}\text { Na maioria das vezes vou às compras quando } \\
\text { tenho dinheiro. }\end{array}$ & \multirow{3}{*}{3,39} & \multirow{2}{*}{ Fem } & \multirow{2}{*}{3,43} \\
\hline & Busco por descontos quando vou às compras. & & & \\
\hline & $\begin{array}{c}\text { Gosto de ir à caça de pechinchas quando vou } \\
\text { comprar algo. }\end{array}$ & & Ms & 3,35 \\
\hline \multirow{3}{*}{ Compra Social } & $\begin{array}{l}\text { Vou às compras com amigos ou familiares } \\
\text { para socializar. }\end{array}$ & \multirow{3}{*}{3,04} & \multirow{2}{*}{ Fem } & \multirow{2}{*}{3,16} \\
\hline & $\begin{array}{l}\text { Gosto de socializar com os outros quando vou } \\
\text { às compras. }\end{array}$ & & & \\
\hline & $\begin{array}{c}\text { Ir às compras com os outros é uma experiência } \\
\text { de relacionamento. }\end{array}$ & & Ms & 2,89 \\
\hline \multirow{3}{*}{ Procurar novidades } & Vou às compras para me atualizar das tendências. & \multirow{3}{*}{2,76} & \multirow{2}{*}{ Fem } & \multirow{2}{*}{3,00} \\
\hline & $\begin{array}{l}\text { Vou às compras para me atualizada sobre as } \\
\text { novidades da moda. }\end{array}$ & & & \\
\hline & $\begin{array}{l}\text { Eu vou às compras para ver os novos produtos } \\
\text { que estão disponíveis. }\end{array}$ & & Ms & 2,47 \\
\hline \multirow{2}{*}{ Eficiência } & $\begin{array}{c}\text { É decepcionante quando tenho que ir a múltiplas lojas } \\
\text { para concluir minha compra. }\end{array}$ & \multirow{2}{*}{3,74} & Fem & 3,55 \\
\hline & $\begin{array}{l}\text { Uma visita a uma loja é boa quando é possível } \\
\text { concluí-la rapidamente. }\end{array}$ & & Ms & 3,96 \\
\hline \multirow{2}{*}{ Realização } & $\begin{array}{l}\text { Me sinto bem por saber que minha ida às compras } \\
\text { foi bem sucedida. }\end{array}$ & \multirow{2}{*}{4,00} & \multirow{2}{*}{ Fem } & \multirow{2}{*}{4,00} \\
\hline & $\begin{array}{c}\text { Numa determinada ida às compras é } \\
\text { importante encontrar } \\
\text { itens que procuro. }\end{array}$ & & & \\
\hline
\end{tabular}


Tabela 2 - Estatística descritiva e Teste T-Student relativos às motivações hedónicas e utilitárias.

As escalas utilizadas para está análise foram montadas com base nas repostas do questionário, as repostas foram compiladas em 8 dimensões e as dimensões quebradas em 3 tipos de escala para direcionar o perfil do consumidor ainda mais.

O teste conhecido como "t de student" é um teste paramétrico que serve para comparar duas médias quando os dados assumirem uma distribuição normal, o teste "t" foi utilizado para avaliar se existia uma diferença significativa entre as médias do sexo feminino e masculino.

\subsection{Análise do comportamento de compra}

Enquanto a pesquisa quantitativa buscou os resultados numéricos e estatísticos da pesquisa, a pesquisa qualitativa buscou explicações para os fenômenos na compreensão das reações humanas, nas crenças e valores. Nesta etapa exploratória realizada paralelamente, foram realizadas entrevistas individuais e pessoais, levando em consideração que o objetivo da pesquisa era compreender e identificar padrões de comportamento, significados e reações dos entrevistados, foi utilizado uma abordagem qualitativa e aberta.

Desta maneira, cada entrevista foi realizada individualmente, com base em um roteiro de perguntas planejado para que os entrevistados pudessem expor suas ideias sobre os assuntos abordados de forma mais livre e sem criar nenhum viés. Os participantes foram questionados sobre seu comportamento de compra, com a intenção de compreender as motivações e as relações que os mesmos estabelecem com as marcas e produtos.

De acordo com "(BAUER e GASKKELL, 2017)", na análise de uma pesquisa qualitativa, o foco é principalmente a exploração do conjunto de opiniões sobre o tema, identificando os diferentes grupos homogêneos, e não homogêneos, de opiniões dentro do segmento social analisado. 
Inicialmente os entrevistados foram questionados sobre suas motivações de compra com base na teoria de necessidade de Maslow. A partir deste panorama, foi identificada uma tendência entre os que se identificaram com a categoria "estima" como maior motivador, a qual normalmente é acompanhada pela categoria de auto realização.

A segunda parte da pesquisa procurou compreender quais os principais fatores motivacionais que os entrevistados levam em consideração na hora de escolher aonde comprar. As respostas foram alocadas em quatro categorias: qualidade, preço, indicação de terceiros e imagem / fama da marca. As respostas no geral foram bem divididas, as categorias preço e qualidade apresentaram o maior número de votos, mas as outras categorias não ficaram muito atrás, pois verificou-se muitos entrevistados que citaram mais de uma categoria em suas respostas.

Uma terceira coletânea de perguntas foi realizada para entender a influencia que os valores dos participantes tinham sobre sua escolha na hora de optar por um produto ou marca. Diante das respostas, observou-se uma tendência de pessoas que se importam com a imagem e os valores que a empresa expõe, mostrando uma forte consciência socioambiental sobre o consumo. É nesta categoria que sem encontram os consumidores que valorizam e deixam de consumir daquelas marcas que vão contra os seus valores. Mesmo nos casos onde foi visto uma média ou baixa consciência de responsabilidade socioambiental no consumo, os respondentes deixaram de realizar uma compra nas marcas com postura negativa.

Os resultados obtidos trouxeram algumas contribuições bem valiosas, avaliou-se que a influencia do valor de compra hedônico sobre a satisfação e sobre o boca-a-boca seria maior do que a influencia do valor de compra utilitário. Por outro lado, a influência do valor de compra utilitário sobra a intenção de recompra seria maior do que a influência do valor de compra hedônico.

\subsection{Opiniões gerais e comparativas dos entrevistados}

Ao analisar o campo das motivações utilitárias, é possível verificar que os entrevistados masculinos apresentam valores médios superiores aos femininos na 
dimensão "Eficiência". Este construto enfatiza a motivação para realizar a compra como um objetivo a ser cumprido, o qual é um resultado compatível com investigações realizadas anteriormente por "Kim (2006)", que identificou um cluster de consumidores funcionais, essencialmente utilitário e composto maioritariamente por homens.

Ao analisar as correlações entre dimensões hedônicas e utilitárias, foi possível verificar que a "Realização" e a "Eficiência" mostram correlações opostas frente às motivações ligadas ao prazer nas compras. O campo "Realização" é compatível com as motivações hedônicas uma vez que apresenta um perfil de compra planejado e assertivo, mas que pode ser agradável, resultado compatível com a perspectiva de "Bardhi e Arnould (2005)" que defendem a ideia de que o consumo pode assumir simultaneamente uma componente hedônica e utilitária.

Já a dimensão "Eficiência" é contrária a uma compra que privilegiao prazer, dado que representa a vontade de comprar o que se tinha previsto o mais rápido possível e sair o quanto antes do espaço comercial. Estes resultados confirmam a análise feita anteriormente, onde os participantes masculinos têm um comportamento de consumo menos hedônico do que os consumidores femininos.

Passando para a análise acerca das variáveis atmosféricas das lojas, concluise que a música demonstrou um impacto positivo na satisfação dos consumidores utilitários, evidenciando que ambientes que sintonizam a música de fundo com a loja, favorecem a compra do produto e o bem-estar pessoal. Isso corrobora com os estudos de "Chebat et al. (2001)", o qual demonstra que a música afeta atitudes por meio do processo cognitivo, ou seja, a música de fundo aumenta as vendas e melhora as atitudes positivas em relação à loja, afeta o tempo de permanência e a compra do cliente.

Como os consumidores se concentram na tarefa de comprar, eles buscam planejar com antecedência quais lojas visitarão e tendem a minimizar o tempo que gastam na área comercial. Neste cenário, a música trabalha para beneficiar essa motivação de compra, facilitando o "sucesso" da compra, por isso a música de fundo ideal na loja tem um importante papel na permanência do consumidor na loja. 
A disposição/layout da loja afetou positivamente a percepção de atendimento ao cliente hedônico. Esses resultados validam o estudo de "Ballantine et al. (2010)", em que estímulos facilitadores, como a organização dos produtos e o layout da loja, afetam positivamente a experiência hedônica dos indivíduos, impactando diretamente na intenção de compra e a percepção do cliente sobre a loja. Nesse sentido, os produtos no ponto de venda precisam estar dispostos de forma atrativa para os consumidores, pois isso implica diretamente na extensão de sua permanência no ponto comercial.

A hipótese de que o valor motivacional dos consumidores moderaria a influência do atendimento na satisfação, não foi significativa. Em outras palavras, o atendimento ao cliente não gerou diferença na satisfação dos consumidores ao considerar motivações hedônicas ou utilitárias. A pesquisa confirmou a ideia de que o valor motivacional do consumidor modera a influencia da satisfação na intenção de recompra, significativa para os consumidores de valor hedônico.

Estes consumidores hedônicos tendem a buscar por experiências agradáveis de compra, eles buscam uma satisfação durante sua permanência na loja, portanto, a satisfação ou insatisfação se observa como consequência da intenção de optar por recomprar ou não na loja.

\section{Conclusão}

Este estudo foi projetado para examinar a relação entre os atributos das lojas, satisfação do cliente e intenção de recompra simultaneamente no contexto das joalherias. Os resultados revelaram que os atributos relacionados à loja, atributos relacionados ao produto e atributos relacionados à qualidade do serviço têm uma influência positiva sobre a satisfação do cliente, se opondo às descobertas de "Chang et al. (2015)", onde se afirmou que o impacto dos atributos relacionados à loja na satisfação do cliente é considerado insignificante.

Estas conclusões podem ajudar os proprietários de joalherias e gerentes de lojas a aprender e aplicar os resultados deste estudo para atender aos níveis de expectativa de seus clientes e satisfazê-los. No caso de atributos relacionados ao produto, deve-se dar mais importância à pureza das joias, à sua durabilidade e às taxas de ouro cobradas pelo joalheiro. A pureza das joias é um critério essencial de qualidade, que é determinado por outros fatores como a taxa de ouro, 
a política de recompra e o valor das joias. A durabilidade das joias leva ao seu uso funcional, e as taxas de ouro têm um impacto direto sobre o preço cobrado ao cliente.

No caso de atributos relacionados à qualidade do serviço, a vestimenta da equipe de vendas, o conhecimento do produto, o conjunto de habilidades e a atitude têm extrema importância. Nas joalherias, a interação entre clientes e vendedores desempenha um papel vital, o vendedor deve ser capaz de entender as necessidades do cliente e deve estar disposto a ajudá-lo. Eles devem ter um conjunto de habilidades e conhecimentos do produto para auxiliar o cliente no processo de compra.

Este estudo constatou também que, para atributos relacionados à loja, a experiência de compra atraente e a imagem positiva da loja são essenciais para a satisfação do cliente. $O$ joalheiro deve engajar o cliente no processo de compra e deve criar uma experiência de compra envolvente para o mesmo, o que consequentemente levará à satisfação do cliente e o engajamento da marca.

A imagem da loja, que também pode ser interpretada como boa vontade dos colaboradores ou a reputação da loja, desempenha um papel importante aumentando a satisfação do cliente, já que os clientes de joalheria preferem visitar lojas com uma boa imagem. Os resultados também confirmam que a satisfação positiva do cliente leva à intenção de recompra. Quando os clientes estão satisfeitos com uma loja, eles defendem a loja e também espalham para os colegas e familiares através de um boca-a-boca positivo. Clientes satisfeitos também patrocinam a loja e visitam a mesma para suas futuras compras, hoje em dia, com a influência das ICT (informação e comunicação tecnológica) e das mídias sociais, o boca a boca eletrônico está se tornando cada vez mais influente.

\subsection{Resultados obtidos}

Os resultados obtidos na pesquisa confirmam que os consumidores hedônicos e utilitários diferem nos procedimentos cognitivos ativados durante o processo de compra, pelo menos no que diz respeito à intenção de recompra. Em geral, existem poucos estudos que abordam este tipo de segmento, por isso este fato reforça a importância de estudos em serviços e varejo na atmosfera dos 
pontos físicos dos lojistas, sobretudo, este estudo contribui para a compreensão da atmosfera das lojas do setor de joias.

A motivação é um dos aspectos mais importantes quando nos referimos ao processo de compra no varejo e das respostas comportamentais. Uma recomendação gerencial, extremamente necessária hoje em dia, é entender as necessidades e desejos dos clientes e o que motiva eles a comprar, para que assim os gestores de marketing possam oferecer-lhes o melhor serviço / experiência de acordo com as orientações e decisões no varejo.

Entender quais motivações são ativadas em uma certa situação e como esta ativação varia entre as diversas possibilidades, constitui um conhecimento valioso sobre que informações os consumidores podem buscar, quais produtos preferem e principalmente quais estratégias de marketing serão mais eficazes para cada tipo de situação.

Agora em relação à atmosfera da loja, uma das variáveis que mais teve destaque nas pesquisas realizadas foi a música de fundo de loja, pois até os consumidores utilitários se sentem mais satisfeitos em ambientes com uma música adequada, assim, é importante saber que estilo musical gera mais conforto, bem-estar e incentiva os consumidores a estenderem sua permanência na loja.

Além disso, um bom layout da loja faz com que os consumidores prestem mais atenção aos produtos e se sintam mais confortáveis na loja, isso favorece a seleção dos mesmos, a compra de produtos e o trabalho dos vendedores. Em termos de gestão, é a partir da exploração da atmosfera da loja e se concentrando no valor motivacional hedônico que os varejistas podem aumentar a satisfação de seus clientes. $O$ fato de que este estudo analisa um produto hedônicos em um ambiente utilitário, acaba diluindo a perspectiva hedonista dessa categoria de produto, por essa razão que hoje em dia se encontram mais consumidores com motivação utilitária e não o contrário.

\subsection{Considerações finais}

Cada vez mais varejistas estão percebendo que o crescimento e a lucratividade de seus negócios estão diretamente ligados aos fatores minimalistas, 
mas que no final são estes que trazem um grande impacto na satisfação e lealdade do consumidor. Em virtude deste panorama, conclui-se que a atmosfera da loja pode ser explorada de várias maneiras com a intenção de melhorar a satisfação e a intenção de recompra dos consumidores na loja.

Por fim, neste estudo pôde-se confirmar a consistência interna nos modelos de “Arnold e Reynolds (2003)", relativos às motivações hedónicas e utilitárias para o consumo. Neste contexto, foi identificado uma tendência de consumidores femininos apresentando valores médios mais altos nos construtos hedônicos, apontando para uma maior predisposição para usufruir das compras como um momento de prazer.

Numa perspectiva divergente, identificamos uma tendência de consumo utilitário para os consumidores do gênero masculino, que apresentam valores médios mais altos em um dos construtores utilitários, ou seja, que prezam pela eficiência da compra, indicando uma tendência de menor envolvimento com o prazer e com a experiência que se pode ter com o momento de consumo.

Este estudo permitiu verificar como os consumidores percebem o ambiente do varejo sob a ótica da motivação e ajudou a entender as motivações dos consumidores utilitários e hedônicos no ambiente de varejo. 


\section{Referências}

AAKER, D. Marcas. Estados Unidos: Brand Equity, 1998.

ADYEN. Relatório varejo 2021 desvenda o consumidor brasileiro no póspandemia. Rio de Janeiro, 2021 Disponível em: $<$ https://www.adyen.com/pt_BR/blog/relatorio-varejo-2021-analisa comportamento-consumidor-brasileiro-no-pos-pandemia>. Acesso em: $01 \mathrm{de}$ novembro. 2021.

AGUIAR, A.C.W.C. (2019). Branded contente - Ferramenta de estratégia de marketing e seu impacto no consumidor. Rio de Janeiro: Centro de ciências sociais - CCS.

CARDOSO, P.A, PINTO, S.C. Consumo hedónico e utilitário e a atitude face à publicidade. Comunicação pública - revista multidisciplinar de comunicação, 8, pp. 99 - 117. Lisboa: 2010.

DAULTANI, Y, GOYAL, K, PRATAP, S. An empirical investigation of the relationship between store attributes and customer satisfaction: $A$ retail operations perspective. Operations and supply chain management, vol. 14, No. 1, 2021, pp. $100-110$.

DIAS, C.D, CRUZ, H.A. (2010) Uma análise da percepção e satisfação dos clientes da empresa FPJ comunicações em Anitápolis/sc. Santa Catarina: XVII SEGeT.

FIGUEIREDO, T.R. (2015). Análise do comportamento do consumidor de joias na cidade do Rio de Janeiro. Rio de Janeiro: Centro de ciências sociais CCS.

Instituto de Pesquisa e Opinião. ABR entre o consumo supérfluo e a necessidade. Rio Branco, 2020. Rio Branco, 2020 Disponível em: < 
https://www.ipo.inf.br/entre-o-consumo-superfluo-e-a-necessidade/>. Acesso em: 23 de setembro. 2021.

LOPES, E.L, TEIXEIRA, J.M, HERNANDEZ, J.M, MORETTI, S.L. (2010). Valores de compra hedônico e utilitário: duas aplicações no varejo especializado. Rio de Janeiro: EnANPAD.

MUNARO, A.C, MARTINS, E, KATO, H.T. O efeito da motivação do consume na percepção dos atributos das lojas de presentes no varejo de joias e sua influência na intenção de recompra. Revista brasileira de gestão de negócios, review of business management, 81 (5), 86-103.

Rock Content Blog. Percepção do cliente: o que é e como saber o que ele pensa sobre a sua empresa. Rio de Janeiro, 2020 Disponível em: < https://rockcontent.com/br/blog/percepcao-do-cliente//>. Acesso em: 12 de outubro. 2021.

SOUZA, F.F, MENGARELLI, A.P.C. (2008) A motivação para o consumo de marcas: A associação do modelo de cadeias meios fins e conhecimento de marca para o contexto turístico. Rio de Janeiro: EnANPAD. 
